University of Wollongong

Research Online

Faculty of Engineering - Papers (Archive)

Faculty of Engineering and Information

Sciences

$1-1-2004$

\title{
Analysis and design of double-sided high-rise steel pallet rack frames
}

Lip H. Teh

University of Wollongong, Iteh@uow.edu.au

Gregory J. Hancock

University of Sydney, g.hancock@usyd.edu.au

Murray J. Clarke

Dematic Pty Ltd, murray.clarke@dematic.com

Follow this and additional works at: https://ro.uow.edu.au/engpapers

Part of the Engineering Commons

https://ro.uow.edu.au/engpapers/633

\section{Recommended Citation}

Teh, Lip H.; Hancock, Gregory J.; and Clarke, Murray J.: Analysis and design of double-sided high-rise steel pallet rack frames 2004, 1011-1021.

https://ro.uow.edu.au/engpapers/633

Research Online is the open access institutional repository for the University of Wollongong. For further information contact the UOW Library: research-pubs@uow.edu.au 


\title{
ANALYSIS AND DESIGN OF DOUBLE-SIDED HIGH- RISE STEEL PALLET RACK FRAMES
}

By Lip H. Teh, ${ }^{1}$ Gregory J. Hancock ${ }^{2}$ and Murray J. Clarke ${ }^{3}$

\begin{abstract}
In routine design of steel storage rack frames, it is far more common to perform 2D rather than 3D linear buckling analyses. In this paper, it is demonstrated that the global buckling behaviour of high-rise steel storage rack frames may not be revealed by 2D buckling analyses as 3D interaction modes are involved. It is shown that the mono-symmetric upright columns of a high-rise rack frame fail in a flexural-torsional mode due to the shear-centre eccentricity of the sections, and that the 3D frame buckling analysis is more reliable in determining the critical members of a rack frame. Current steel storage rack design standards combine independent 2D flexural buckling analyses and simplified flexural-torsional buckling analysis of individual columns to account for 3D behavior. Comparisons between the buckling stresses of the rack columns determined from 3D buckling analyses and the buckling stresses determined in accordance with the steel storage racking standards are presented. It is concluded that the use of 2D analysis based procedures can lead to poorly proportioned pallet rack structures in terms of safety or economy. By comparing the buckling analysis results using 3D beam elements of varying degrees of refinement to each other, it is also demonstrated that the beam elements available in most commercial frame analysis programs are not sufficiently refined for accurate 3D buckling analyses of high-rise rack frames composed of mono-symmetric thin-walled open sections.
\end{abstract}

\footnotetext{
${ }^{1}$ Post-doctoral Fellow, Dept. of Civ. Eng., Univ. of Sydney, NSW 2006, Australia

${ }^{2}$ BHP Steel Prof., Dept. of Civ. Eng., Univ. of Sydney, NSW 2006, Australia

${ }^{3}$ Struct. Engrg. Manager, Mannesmann Dematic Colby Pty Ltd, Belrose, NSW 2085, Australia
} 


\section{Introduction}

Steel storage racks, as their name implies, are used to store industrial goods such as paper rolls and barrels of chemicals in their shelves. There are two principal types of racking systems, i.e. the adjustable pallet racking system and the drive-in racking system. A doublesided adjustable pallet rack frame is shown in the foreground of Fig. 1. This frame results from two single-sided frames being placed back-to-back, with backties (or rack spacers) connecting the adjacent back columns. This paper is concerned with the analysis and design against structural instability of double-sided pallet rack frames, in particular the high-rise rack frame depicted in Fig. 2. In routine design, 2D analyses in the down-aisle and in the crossaisle directions are performed independently. However, it will be shown that the 3D buckling modes of a high-rise pallet rack frame may not be captured by such 2D analyses. The safety and economy of a high-rise pallet rack frame depends on accurate predictions of its buckling modes.

In practice, design checks of steel storage racks against member buckling are specified in the form of interaction equations which compare the nominal member (axial and moment) capacities against the design member forces determined from either first-order or secondorder elastic analyses. In the absence of distortional buckling, the nominal member compression capacity of a given section is assessed on the basis of the member effective lengths for column buckling about orthogonal axes and twisting. In recent years, there has been a trend towards the use of rational frame buckling analysis at the expense of the conventional method of determining the effective lengths of a member from its end-restraint stiffnesses and the frame bracing conditions. In a rational frame buckling analysis, the linear buckling load factor of a frame (which is the factor on the applied design load at which the frame buckles elastically with negligible pre-buckling deformations) is first determined using 
a computer program based on the matrix structural analysis method, and the elastic "buckling load" of each compression member is computed through multiplying its design axial force by the frame buckling load factor. The member effective length is then obtained by reference to the member elastic buckling load in the case it is simply supported (for which the effective length factor is unity). The use of rational frame buckling analysis, although not without problems (White and Hajjar 1997), obviates many difficulties involved in the proper application of the conventional method (Cheong-Siat-Moy 1986, 1995, Aristizabal-Ochoa 1997, ASCE 1997). However, due to the size and the topology of a typical steel storage rack structure, full 3D frame buckling analysis is rarely if ever carried out for the purpose of determining the effective length of the compression members.

The steel storage racking standards AS 4084 (SA 1993a), RMI Specification (RMI 1997) and FEM 10.2.02 (FEM 1998) allow the use of independent 2D buckling analyses in the downaisle and in the cross-aisle directions. Simplified procedures may be used to simulate the transfer of horizontal forces among inter-connected parallel frames, and to account for other aspects of 3D behaviour in 2D models (Smith and Cruvellier 1991). However, in general both the elastic buckling loads (down-aisle and cross-aisle) predicted with independent 2D buckling analyses are higher than the 3D buckling load since 3D buckling interaction modes are suppressed in the $2 \mathrm{D}$ models. The critical members determined through $3 \mathrm{D}$ frame buckling analysis may also differ from those determined through 2D buckling analysis.

Another major consideration in assessing the stability of pallet rack columns is the fact that they are usually composed of mono-symmetric open sections and may undergo flexuraltorsional buckling. The orientation of the axis of symmetry is usually in the plane of the upright frames so that flexural-torsional buckling is associated with down-aisle buckling deflections. The flexural-torsional buckling stress of a pallet rack column is therefore normally computed through substituting the flexural buckling stress determined from the 2D 
down-aisle buckling analysis and the torsional buckling stress into a flexural-torsional buckling formula, as specified in Clause 3.4.3 of AS/NZS 4600 (SA/SNZ 1996) and Clause C3.4 of the AISI Specification (AISI 1996). However, there are a number of shortcomings associated with this approach as described later.

The computer program used to carry out 3D linear buckling analyses of the double-sided frame models in this paper is largely based on the research results previously reported by the authors (Teh 1998, Teh and Clarke 1997, 1998, 1999), with section mono-symmetry and thinwalled torsion being incorporated into the software. The primary aim of the paper is to investigate the potential implications of using 2D procedures specified in steel storage racking standards to determine the buckling stress of a mono-symmetric column. A secondary aim is to investigate the implications of using "simple" 3D beam elements available in commercial frame analysis programs to determine the buckling load factor of a steel pallet rack frame.

Earlier studies on various aspects of steel storage racks have been reported by Pekoz (1979), Hancock (1985), Roos and Hancock (1986), Lewis (1991), Davies (1992), Dunai et al. (1997), Tide and Calabrese (1998), Baldassino and Hancock (1999), Olsson et al. (1999), Baldassino et al. (2000) and Godley et al. (2000), among others.

\section{Topology of rack frames and member properties}

In adjustable pallet racks, the stored goods generally rest on pallets that are supported by pairs of horizontal beams connecting the laced columns (upright frames). Figure 1 shows an "unloaded" double-sided frame in the foreground, and a loaded one in the background. As can be seen from the figure, the pallets in the bottom storeys do not create loading on the frames. The pallet beams are locked-in to the columns by means of proprietary moment connections that are easily installed or removed so that the height of the beams can be varied according to 
storage requirements (hence the name "adjustable pallet rack"). Although the double-sided frames shown in Fig. 1 are not modelled in this paper, the basic topology and the way the pallet loads are transferred to the columns are similar to those modelled in this paper.

The high-rise rack frame model depicted in Fig. 2, which is studied in this paper, represents only the portion that is assumed to share a spine tower in the structural analysis of rack substructures. In reality, a series of such frames are placed end-to-end in a continuous fashion in the down-aisle direction to form a racking system up to 200 metres long. The seven-bay double-sided frame depicted in Fig. 2 is therefore a sub-structure of a racking system that has one spine tower for every eight bays. Furthermore, for space and operational efficiency, a number of parallel frames are often grouped together as shown in Fig. 3, with each group typically consisting of four or five double-sided frames on the inside and two single-sided frames on the outside. The top of the rack frames are commonly connected to each other by horizontal trusses in order to provide additional frame stability.

The geometry, the section properties and the pallet loads of the double-sided frame assumed in the present work are representative of actual high-rise pallet rack frames. Each frame is 27 metres high, comprising 13 storeys (called 12 levels in storage rack terminology as the bottom storey is not loaded) ranging from $1125 \mathrm{~mm}$ to $2800 \mathrm{~mm}$ in depth to accommodate the varying sizes of the pallets. The width of each bay is $2900 \mathrm{~mm}$ as measured between the column centre-lines, resulting in a total frame length of 20.3 metres since each frame consists of seven bays. Each upright frame is $1100 \mathrm{~mm}$ wide (measured between the column centrelines), and the distance between two upright frames placed back-to-back in the double-sided frame is $450 \mathrm{~mm}$ (which is also the backtie length). Table 1 lists the beam levels and the backtie elevations. The level numbers in the first column are defined in Fig. 4, which shows the front view of the double-sided frame (see the next paragraph for further discussion on the backtie elevations). 
With regard to the backties, those in the spine tower also serve as anchorage for the downaisle braces, as depicted in Figs. 2 and 5. The section details are shown in Fig. 6. Therefore, the approximate positions of the backties can be identified from the ends of the down-aisle braces in Fig. 4. It may be noted that only tension down-aisle braces are included in the linear buckling analyses as the compression braces are ineffective at buckling.

Each shelf in the second and third storeys carries a pair of 1-tonne pallets, while that in the fourth through the eleventh storey carries 1.5-tonne pallets, and that in the top two storeys carries 2-tonne pallets. Such an arrangement, in which the heavier loads are stored in the higher shelves, is used in practice in order to minimise the beam vertical spacings in the lower sections and hence the "down-aisle" effective length factors of the more heavily loaded members. Table 2 lists the cross-section area $A$, the second moments of area about the major and the minor axes $I_{z}$ and $I_{y}$, and the torsion constant $J$ of the pallet beams, which are sized in accordance with the pallet loads that have to be carried by the beams. Note that the top beam is not loaded with pallets. The beams are rectangular hollow sections and hence resist torsion mainly by St. Venant torsion (no warping torsion).

The backties in the spine tower, to which the $100 \times 6 \mathrm{~mm}$ flat strip down-aisle braces are anchored, are composed of $75 \times 75 \times 3$ mm square hollow sections. Such backties are normally welded to plates bolted to the upright columns, and in the present study the backtie-to-upright connections are assumed to be rigid. However, the exact anchorage positions of the braces above/below the backtie centre-lines are modelled in the buckling analyses, as evident in Fig. 5. The 112.5-mm offset induces torsion in the backties, and hence additional bending moments in the upright columns. The backties which are not in the spine tower (rack spacers only) are composed of $50 \times 50 \times 3 \mathrm{~mm}$ square hollow sections. 
As depicted in Fig. 5, the lower portion of each upright frame is reinforced in the cross-aisle direction with double bracing that extends up to the fifth storey, while the upper portion is single-braced only. The spacing between the double-bracing points in an upright column is $600 \mathrm{~mm}$. Two mono-symmetric cold-formed sections of similar geometry but different thicknesses are commonly used for the upright columns in the lower and the upper portions, respectively. The cross-section properties of the two column sections and the cross-aisle braces assumed in the present study are listed in Table 3- the major z-axes of the column sections (the axes of symmetry as shown in Fig. 7) are in the plane of the upright frames. The braces are assumed to be pinned to the columns about the horizontal axis, so the corresponding second moment of area is assumed to be zero in the frame buckling analysis (the $y$ and $z$ subscripts are the local axes of the respective members, and are not global axes). It is also assumed that there is no torsional warping transmission between the columns and the braces, and that the braces are free to warp under torsion, so the warping constant $C_{w}$ of the braces is also assumed to be zero in the buckling analysis. However, the brace-to-upright joints are assumed to be perfectly tightened as far as rotation about the vertical axis is concerned. The last column of Table 3 lists the eccentricity of the shear-centre with respect to the centroid of each section. The shear-centres of the upright columns are located outside the upright frame, i.e. away from the cross-aisle braces.

The beam-to-column connections are assumed to be semi-rigid in bending about the horizontal axis as well as about the vertical axis. In general, the connection stiffness is significantly influenced by the wall thickness of the column section. In this paper, it is assumed that the average rotational (bending) stiffnesses of the connection about the horizontal axis in the lower and in the upper columns are $500 \mathrm{kN} . \mathrm{m} / \mathrm{rad}$ and $300 \mathrm{kN} . \mathrm{m} / \mathrm{rad}$, respectively. These values are based on the stiffnesses measured in the laboratory tests of certain proprietary moment connections between slightly smaller sections. The corresponding 
values about the vertical axis are $200 \mathrm{kN} . \mathrm{m} / \mathrm{rad}$ and $120 \mathrm{kN} . \mathrm{m} / \mathrm{rad}$. The length of a beam-tocolumn connection is taken to be half the web width of the column, which is $60 \mathrm{~mm}$ for the upper as well as the lower columns. As each bay is $2900 \mathrm{~mm}$ wide, the length of a shelf beam in the rack frames is equal to $2780 \mathrm{~mm}$. The connection element used in the present work was presented by Li et al. (1995), which can model the bending, twisting, axial and shear stiffnesses of a connection. In this paper, the axial, the shear and the twist stiffnesses are assigned the values of $5000 \mathrm{kN} / \mathrm{mm}, 10^{6} \mathrm{kN} / \mathrm{mm}$ and $1000 \mathrm{kN}$.m/rad, respectively. The axial, the shear and the torsional flexibilities of the beam-to-column connections are therefore effectively ignored in the present analyses owing to the artificially large stiffnesses relative to the sustained forces or torque. However, their effects on the buckling of the rack frames are insignificant compared to those due to the bending flexibility about the horizontal axis.

As the beam-to-column connections are relatively flexible, for the purpose of linear buckling analysis, it is assumed that the pallet loads are transferred to the columns as vertical loads only, which is indeed justified for the inner columns of the racking system. (As mentioned previously, the seven-bay frame represents the sub-structure of a racking system that has one spine tower for every eight bays.) It is also assumed that the gravity loads act through the column centroids, and are therefore eccentric with respect to the shear centres, which are outside the upright frames as mentioned previously. In accordance with AS 4084 (SA 1993a), an initial out-of-plumb of $0.2 \%$ in the down-aisle direction is applied to the seven-bay frame assuming no connector looseness. This initial out-of-plumb is simulated through the use of notional horizontal (plan) forces equal to $0.2 \%$ of the gravity loads. The transfer of horizontal loads between the aisle columns and the back columns is effected mainly through the horizontal braces which connect the pairs of pallet beams with each other in the spine tower. The horizontal braces are composed of $50 \times 50 \times 6 \mathrm{~mm}$ equal angle sections. Table 4 lists the cross-section properties of the horizontal braces, the down-aisle braces and the backties. 
The present work does not simulate the shear flexibility of the upright frames (laced columns) caused by the looseness of the cross-aisle bracing connections, which may significantly reduce the cross-aisle buckling load of the frames. However, in general the reduced cross-aisle buckling load is still higher than the flexural-torsional buckling load of the critical upright column, and in most cases, also higher than the down-aisle buckling load of the corresponding multi-bay frames. Due to the topology of the rack frame considered in this paper as depicted in Figs. 2 and 3, cross-aisle buckling of the frame models is effectively circumvented and the issue concerning the frame shear flexibility becomes irrelevant.

It may also be noted that due to the ground bracing in the spine tower (see Figs. 2 and 4), the rigidity of the base-column connections is an insignificant factor as far as the frame buckling loads are concerned. Accordingly, the linear buckling analysis results presented in this paper are equally valid whether the base-column connections are pinned or rigid.

For the purpose of the present work, no load factors on the applied pallet loads are used in the linear buckling analyses, and no initial out-of-plumb in the cross-aisle direction is assumed in any model of the double-sided frame. The issue concerning the number of (cubic) elements per member used to model a steel frame is largely immaterial to the buckling analyses of high-rise storage rack frames for two reasons. Firstly, for a high-rise storage rack frame, the down-aisle flexural buckling is dominated by the $P-\Delta$ effect and so one element per member is sufficiently accurate (Teh 2001). Secondly, the truss bracing of an upright frame and the presence of backties or rack spacers necessitate the use of several elements per storey column. 


\section{Full 3D linear buckling analyses}

Four 3D linear buckling analyses are performed, starting from the least accurate element to the most accurate one. Such progressive analyses may give valuable insights into the behaviour of the steel rack structure under different conditions, and also illustrate the pitfalls of using simpler elements available in most commercial frame analysis programs.

In Model 1, the upright columns are assumed to twist uniformly. This assumption means that torsion in the upright columns is resisted solely by the uniform (St. Venant) torsion, with the torsion constant normally denoted as $J$. The spatial beam element used in this model is a direct extension of the planar element used for 2D frame analysis (Jennings 1968) with the addition of the linear (uniform) torsion stiffness (Meek and Tan 1984), so the shear-centre eccentricity of the cross-section is ignored in this model. In addition, this element is unable to detect torsional buckling of an isolated column (Teh and Clarke 1998). Such an element is used in many commercial frame analysis programs claimed to have a 3D frame analysis capability. The predicted linear buckling load factor using this simple element is 2.14 (see Table 5), and the associated buckling mode is shown in Fig. 8. The low St. Venant torsional rigidity means that torsion of the uprights occurs with motion in opposed directions of the front and back upright frames.

For the buckling analysis of the Model 2, the simple element used in the first model is augmented with the Wagner effect term (Timoshenko and Gere 1961, Trahair 1993), rendering it comparable to some beam elements proposed in the literature (Chan and Zhou 1994). As with Model 1, the buckling of the uprights is alternate flexural-torsional without down-aisle sway as depicted in Fig. 9. However, the present buckling load factor of 0.45 is considerably lower due to the Wagner effect. Such a phenomenon is possible if the columns are composed of open sections that are weak in torsion. The possibility of the upright frames of a double- 
sided frame to buckle in opposite directions is mentioned in the European rack design code (FEM 1998).

The elements used in Models 1 and 2 ignore torsional warping rigidity in the upright columns and therefore produce low buckling load factors. In Model 3, a (two-noded) spatial beam element with 7 degrees of freedom per node is used to model the upright columns. The seven degrees of freedom at each node comprise three translational degrees of freedom, three rotational degrees of freedom plus a warping degree of freedom. The warping degree of freedom is included to account for the fact that torsion in an upright column is not uniform, and that the cross-section tends to displace longitudinally (warp) under torsion. Such an element is comparable to that presented by Conci and Gattass (1990) and Hsiao and Lin (2001). In this paper, it is assumed that torsional warping at the column bases is fully restrained, and that torsional warping is continuous throughout the upright columns. It was found that the inclusion of torsional warping rigidity, represented by the warping constants $C_{\mathrm{w}}$ of the upright columns, drastically increases the computed buckling load factor from 0.45 (second model) to 2.95 as given in Table 5. The buckling mode also changes to overall sway, as shown in Fig. 10. It should be kept in mind, however, that the shear-centre eccentricity of the mono-symmetric sections of the upright columns is ignored in all the first three models.

In Model 4, a spatial beam element that accounts for torsional warping and shear-centre eccentricity of the cross-section is used. This element has been verified against the classical flexural-torsional buckling solutions for columns with mono-symmetric and asymmetric cross-sections which may be subjected to torsional warping (Teh 2001), and is comparable to the element presented by Conci (1992). A beam element which accounts for the Wagner effect, torsional warping and shear-centre eccentricity from the centroid has also been formulated by Hsiao and Lin (2000), but in their formulation the axial load needs not act through the centroid. Inclusion of the shear-centre eccentricity with respect to the axial loads 
applied to the centroids of the upright sections reduces the buckling load factor of the double-sided frame from 2.95 to 2.48, and the buckling mode shown in Fig. 11 is no longer a sway one. The flexural-torsional buckling mode in this more comprehensive model is restricted to the outermost columns, especially those on the end of the frame away from the spine tower from Storey 5 through Storey 7, as evident in Fig. 11. It can be seen that the back

columns are torsionally restrained by the rack spacers which connect the adjacent back columns, and are thus less susceptible to flexural-torsional buckling than the aisle columns.

Table 5 summarises the 3D linear buckling analysis results using the four different models. The results of Model 4, which is believed to be the most accurate and hence the benchmark solution, are used in the following sections to verify the accuracy of 2D analysis based procedures in determining the flexural-torsional buckling stresses of the mono-symmetric upright column sections.

\section{Torsional buckling stresses and the flexural-torsional buckling formula}

In this section, the torsional buckling stresses of the upright columns are computed based on the assumption that the torsional effective length factor is 0.8 (SA 1993a, RMI 1997). The reference torsional length is the unbraced length of the upright column, which is $600 \mathrm{~mm}$ for the double-braced lower column, or $1200 \mathrm{~mm}$ for the single-braced upper column. The double-braced lower columns and the single-braced upper columns can be seen in Figs. 2, 3 and 5.

The polar radius of gyration $r_{x}$ about the shear centre of a mono-symmetric section is 


$$
r_{x}=\sqrt{\frac{I_{z}+I_{y}}{A}+z_{s}^{2}}
$$

in which $I_{z}$ and $I_{y}$ are the second moments of area about the principal axes, $A$ is the crosssection area, and $z_{s}$ is the shear-centre eccentricity from the centroid measured along the $z$ axis of symmetry.

The elastic torsional buckling stress of a compression member is (Timoshenko and Gere 1961, Hancock et al. 2001)

$$
f_{o x}=\frac{G J}{A r_{x}{ }^{2}}\left(1+\frac{\pi^{2} E C_{w}}{G J l_{e x}{ }^{2}}\right)
$$

in which $E$ and $G$ are the Young's and the shear moduli, respectively, while $J$ and $C_{w}$ are the torsion and the warping constants, and $l_{e x}$ is the torsional effective length. For steel, the values of $E$ and $G$ are commonly assumed to be $2 \times 10^{5} \mathrm{MPa}$ and $8 \times 10^{4} \mathrm{MPa}$, respectively.

Substituting the relevant section properties from Table 3 gives the polar radius of gyration $r_{x}$ about the shear centre of the lower column section as $98.6 \mathrm{~mm}$, and that of the upper column section as $103.0 \mathrm{~mm}$. Further substituting these values and the geometric properties given in Table 3 into Equation (2), the torsional buckling stresses are $2768 \mathrm{MPa}$ for the lower column $\left(l_{e x}=0.8 \times 600 \mathrm{~mm}\right)$, and $682 \mathrm{MPa}$ for the upper column $\left(l_{e x}=0.8 \times 1200 \mathrm{~mm}\right)$.

The flexural-torsional buckling stress $f_{\text {oxz }}$ of a mono-symmetric section can be computed from the torsional buckling stress $f_{o x}$ and the flexural buckling stress about the axis of symmetry $f_{o z}$ as (SA/SNZ 1996, AISI 1996)

$$
f_{o x z}=\frac{f_{o x}+f_{o z}-\sqrt{\left(f_{o x}+f_{o z}\right)^{2}-4\left[1-\left(z_{s} / r\right)^{2}\right] f_{o x} f_{o z}}}{2\left[1-\left(z_{s} / r\right)^{2}\right]}
$$


Equation (3) is strictly valid only for the columns which have the same effective length for torsional and flexural buckling modes (Chajes and Winter 1965, Hancock et al. 2001). In general, the torsional and the flexural effective lengths of an upright column are different from each other, and the application of the flexural-torsional buckling formula leads to underestimation of the flexural-torsional buckling stress provided the flexural and the torsional buckling stresses are not significantly overestimated (Roos and Hancock 1986, Attard 1992).

\section{The planar model}

A 28-bay plane frame is used to model the double-sided frame shown in Fig. 2, which was previously studied using 3D linear buckling analyses. In the planar model, the spine tower is split into two so that each of the split spine towers restrains a 14-bay plane frame, as illustrated in Fig. 12. The 14-bay frames represent the single-sided frames constituting the double-sided frame, and the split spine towers are joined together with rigid links at the beam levels (rather than at the backtie elevations for the sake of simplicity in modelling). The rigid links are assigned a very large value of axial stiffness.

The two 7-bay frames of each single-sided frame component, which are composed of back columns and aisle columns, respectively, are linked together with pin-ended bars at the beam levels, as shown in Fig. 12. The axial stiffness of the bars matches the down-aisle stiffness of the horizontal braces between the back column and the aisle column in the spine tower. In the present study, the length of the rigid links between the split spine towers and the length of the bars between the 7-bay frames are taken to be the same as the beam length for the sake of simplicity in modelling. 
As shown in Fig. 6, the flat strip down-aisle braces are not connected directly to the SHS backties, but are pinned to anchor plates welded to the backties. Such an arrangement creates a vertical offset of $112.5 \mathrm{~mm}$ above or below the backtie elevations, and this offset is modelled in the plane frames. The flexural and the torsional flexibilities of the backties, which are composed of square hollow sections, can be simulated using semi-rigid connections between the flat-plate anchors and the upright columns at the backtie elevations. However, it has been found from preliminary studies that the simulation of backtie flexibilities in the plane frame model does not have significant effects on the sway buckling load, and thus the 2D buckling load factor presented in this paper is fairly independent of the simulation of backtie flexibilities. Nevertheless, the modelling of backtie flexibilities is implemented in the present study.

For the purpose of comparing the flexural-torsional buckling stresses, the controlling design members are assumed to be the aisle columns of the double-sided frame which buckle flexural-torsionally in Fig. 11. These are the column members of Storeys 5 and 6, representing the double-braced and the single-braced upright frames, respectively. The design members are indicated by the dashed ellipse in Fig. 2. Note also that the effective lengths of the base columns, which are the most heavily loaded members, are much smaller than those of the storey columns.

\section{Rational buckling stresses}

The buckling load factor of the 28-bay plane frame was found to be 3.10 with the sway buckling mode depicted in Fig. 12. This buckling load factor is slightly higher than the sway buckling load factor of the 3D model which ignores shear-centre eccentricity (see Fig. 10 for the buckling mode), which is 2.95 . The small discrepancy is likely due to the assumptions 
adopted in modelling the bracing systems of the planar model. However, the buckling load factor of the planar model is $25 \%$ higher than the flexural-torsional buckling load factor of the double-sided frame, which is 2.48 as given in Section 3 for the fourth model (see Fig. 11 for the buckling mode). As mentioned previously, the 3D buckling analysis results of the fourth model are treated as the "benchmark" solutions.

The flexural-torsional buckling stress of the design member for the double-braced lower column, which is the aisle column of Storey 5, determined from the 3D rational buckling analysis is

$$
f_{o x z}=\frac{{ }^{s} P \times 2.48}{A}=\frac{127893 \times 2.48}{800}=396 \mathrm{MPa}
$$

while the flexural buckling stress about the axis of symmetry determined from the 2D rational buckling analysis is

$$
f_{o z}=\frac{{ }^{p} P \times 3.10}{A}=\frac{128377 \times 3.10}{800}=497 \mathrm{MPa}
$$

The variables ${ }^{\mathrm{s}} P$ and ${ }^{\mathrm{p}} P$ in Equations (4) and (5) are the axial compressive forces in the design member determined from 3D and 2D linear elastic analyses, respectively, using a load factor of unity.

The flexural-torsional buckling stress of the lower column as computed from Equation (3) using the torsional buckling stress of $2768 \mathrm{MPa}$ determined in Section 4 and the flexural buckling stress of $497 \mathrm{MPa}$ computed in Equation (5) is $437 \mathrm{MPa}$. This value is $11 \%$ higher than the flexural-torsional buckling stress of $396 \mathrm{MPa}$ computed based on the 3D rational buckling analysis and given by Equation (4). 
Using the same formulae, the flexural-torsional buckling stress of the design member for the upper column, which is the aisle column of Storey 6, was computed to be 469 MPa based on the 3D rational buckling analysis, and the flexural buckling stress about the axis of symmetry was computed to be $586 \mathrm{MPa}$ based on the 2D rational buckling analysis. Since the torsional buckling stress of the upper column is $682 \mathrm{MPa}$ as computed in Section 4, Equation (3) yields a flexural-torsional buckling stress of $336 \mathrm{MPa}$, which is $28 \%$ lower than the value of $469 \mathrm{MPa}$ obtained in the 3D rational buckling analysis.

Hence, the values computed from Equation (3) based on the 2D rational buckling analysis results and the torsional effective length factor of 0.8 are significantly higher and lower than those determined through the 3D rational buckling analysis for the lower and the upper columns, respectively. This means that the present $2 \mathrm{D}$ procedure is inconsistent with the 3D rational buckling analysis.

\section{$7 \quad$ Alternative 2D procedures}

Alternative analysis procedures for determining the flexural buckling stress of a member of a racking system are given in the commentary to the Australian steel storage racking standard (SA 1993b). These procedures involve the calculation of the reduced stiffness of a pallet beam due to the semi-rigidity of the joint. Different formulae are employed to compute the reduced stiffness depending on whether the rack frame is braced or unbraced against side-sway. The reduced stiffness of the pallet beam is then used in computing the stiffness ratios $G_{A}$ and $G_{B}$ to find the effective length factor of the member from the steel standard AS 1250-1981 (SAA 1981). In this section, the effective length factors of the design members (the aisle columns of Storeys 5 and 6 as circled in Fig. 2) are determined from Figure 4.6.3.3 of the recent standard AS 4100-1998 (SA 1998). 
The rack frame is first assumed to be braced against side-sway, so the reduced stiffness of a pallet beam is (SA 1993b)

$$
\left(\frac{I_{b}}{L_{b}}\right)_{\text {red }}=\frac{I_{b} / L_{b}}{1+2 E I_{b} / L_{b} F}
$$

in which $I_{b}$ is the second moment of area of the pallet beam, $L_{b}$ is the beam length, and $F$ is the beam-to-column connection stiffness. Substituting the relevant values given in Table 2 and Section 2 into Equation (6), the reduced stiffness of the pallet beams in Storey 5 are 365.8 $\mathrm{mm}^{3}$, and that of the pallet beam above Storey 6 is $306.1 \mathrm{~mm}^{3}$.

The stiffness ratio at one end of a compression member is calculated as (SA 1998)

$$
G=\frac{\Sigma(I / L)_{\text {column }}}{\Sigma(I / L)_{\text {beam }}}
$$

Using the appropriate values given in Tables 1 and 3 and the reduced stiffnesses of the pallet beams computed previously, the stiffness ratios $G_{A}$ and $G_{B}$ of the lower column are 3.2 and 2.9, respectively; while those of the upper column are 2.9 and 3.0. The approximate effective length factor of both columns as determined from Figure 4.6.3.3(a) of AS 4100-1998 (SA 1998) is then 0.89, which means that the effective length of the column in Storey 5 is 1958 $\mathrm{mm}$ and that of the column in Storey 6 is $1913 \mathrm{~mm}$.

The elastic flexural buckling stress of a column of effective length $l_{e z}$ is

$$
f_{o z}=\frac{\pi^{2} E I_{z}}{A l_{e z}{ }^{2}}
$$

from which the flexural buckling stress about the axis of symmetry of the lower column was computed to be $837 \mathrm{MPa}$, and that of the upper column was found to be $899 \mathrm{MPa}$. 
Substituting these values to Equation (3), the flexural-torsional buckling stress of the lower column in the braced frame is $675 \mathrm{MPa}$, and that of the upper column is $413 \mathrm{MPa}$. These values are an overestimation of $70 \%$ and an underestimation of $12 \%$ of the corresponding values determined through the 3D rational buckling analysis, which are $396 \mathrm{MPa}$ and 469 $\mathrm{MPa}$, respectively.

Thus, compared to the previous procedure based on 2D rational buckling analysis, the assumption of a braced frame in the present 2D procedure exacerbates the overestimation of the flexural-torsional buckling stress of the lower column and reduces the underestimation of same of the upper columns.

The reduced stiffness of a pallet beam in an unbraced rack frame is (SA 1993b)

$$
\left(\frac{I_{b}}{L_{b}}\right)_{\text {red }}=\frac{I_{b} / L_{b}}{1+6 E I_{b} / L_{b} F}
$$

from which the reduced stiffness of the pallet beam in Storey 5 is $230.8 \mathrm{~mm}^{3}$, and that of the pallet beam in Storey 6 is $168.5 \mathrm{~mm}^{3}$. The computed stiffness ratios $G_{A}$ and $G_{B}$ of the lower column are 5.1 and 4.6, respectively; while those of the upper column are 4.6 and 5.5. From Figure 4.6.3.3(b) of AS 4100-1998 (SA 1998), the approximate effective length factor of both columns is 2.1. Using Equation (8), the flexural buckling stress of the lower column in the unbraced frame is $150 \mathrm{MPa}$, and that of the upper column is $161 \mathrm{MPa}$. The resulting flexuraltorsional buckling stresses computed using Equation (3) are $144 \mathrm{MPa}$ and $135 \mathrm{MPa}$, respectively. These are $64 \%$ and $71 \%$ lower than the corresponding values determined through the 3D rational buckling analysis. 
Thus it is seen that while the assumption of a braced frame leads to overestimation of the flexural-torsional buckling stress of the lower column, the assumption of an unbraced frame leads to considerably over-conservative estimates.

In lieu of the procedure described above, the Australian steel racking standard (SA 1993a) and the RMI Specification (RMI 1997) allow the simple assumptions of a flexural effective length factor of 1.0 for a braced frame, and a flexural effective length factor of 1.7 for an unbraced frame. The use of an effective length factor of 1.0 magnifies the underestimation of the flexural-torsional buckling stress of the upper column, while an effective length factor of 1.7 still leads to significant underestimation of the flexural-torsional buckling stresses.

Table 6 summarises the overestimations and the underestimations of the elastic flexuraltorsional buckling stresses by the 2D analysis based procedures described previously in this paper. It can be seen that in all cases the errors are significant and perhaps unacceptable.

In the past fifteen years, considerable efforts have been spent on improving the accuracy of the $G$-factor approach in determining the effective length factors of columns in braced, partially braced and unbraced frames (Bridge and Fraser 1987, Duan and Chen 1988, 1989, Hellesland and Bjorhovde 1996, Kishi et al. 1997, Essa 1997, Cheong-Siat-Moy 1999). However, at best the improved $G$-factor based methods can only determine the flexural effective length factors with high accuracy, but do not solve the problem of determining the appropriate torsional effective length factors of upright columns. Furthermore, as mentioned previously, the flexural-torsional buckling formula expressed by Equation (3) is strictly valid only for the columns which have the same effective length for flexural and torsional buckling modes.

With the help of modern desktop computer technology and appropriate frame analysis software, there is little reason for not conducting 3D frame buckling analysis for the purpose 
of determining the flexural-torsional buckling stress of an upright member. A rational frame buckling analysis either predicts the elastic buckling stress of a member accurately or underestimates it, unless the sub-structuring of the racking system is poorly done. For the less critical members, storey or subassembly buckling analyses may be carried out in lieu of a complete frame buckling analysis in order to obtain more accurate estimates of the buckling stresses (White and Hajjar 1997).

\section{Conclusions}

This paper has presented new studies regarding the three-dimensional frame buckling behaviour of high-rise adjustable pallet racks and the accuracy of $2 \mathrm{D}$ analysis based procedures in determining the elastic flexural-torsional buckling stress of an upright section. The topology, the member sizes and the pallet loads of the rack model studied in the present work are representative of those used in the logistics industry.

It was demonstrated that there is a problem in using the beam elements available in many commercial frame analysis programs which neglect torsional buckling and the coupling between axial, flexural and torsional deformation modes at the element level (Model 1). This neglect may result in significant overestimation of the 3D elastic buckling load of a steel frame composed of open sections that are weak in torsion. Conversely, if torsional warping of the upright column sections is ignored in the analysis while the Wagner effect is included (Model 2), then the predicted 3D buckling load of a rack frame may be unrealistically low. For sections with significant warping rigidity, the resistance to non-uniform torsion afforded by warping restraints (Model 3) increases the buckling load of the double-sided frame by more than five times as the buckling mode changes from alternate flexural-torsional to overall sway. However, it was also shown that the shear-centre eccentricities of the mono-symmetric 
sections cause the upright columns (Model 4) to buckle flexural-torsionally in a localised region without sway at a lower buckling load.

The difference in the predicted buckling load factor between Model 1 as commonly used in commercial frame analysis software and Model 4 as described in the paper for the doublesided frame is only $16 \%$. However, this value may vary significantly depending on the particular frame topology. Furthermore, the 3D buckling modes predicted using beam elements with varying degrees of refinement are very different from each other. The use of a beam element that accounts for torsional warping and shear-centre eccentricity enables a more accurate identification of the critical members of a high-rise pallet rack frame.

The use of the 2D procedure based on either the $G$-factor approach or the simple effective length factor of 1.0 for a "braced frame" results in overestimation for the elastic flexuraltorsional buckling stresses of the upright columns even though the adjustable pallet rack frame is restrained against down-aisle sway by vertical diagonal braces in the spine tower. On the other hand, the assumption of an unbraced frame in the $G$-factor approach or of a simple effective length factor of 1.7 results in underestimation of same.

Compared to the $2 \mathrm{D}$ procedures mentioned in the preceding paragraph, the procedure based on 2D frame buckling analysis yields the best estimates for the elastic flexural-torsional buckling stresses of the upright columns. However, 2D frame buckling analysis is not necessarily consistent with 3D buckling analysis. The use of 2D rational buckling analysis in conjunction with an assumed torsional effective length factor of 0.8 results in an overestimation of the flexural-torsional buckling stress of $11 \%$ for the lower column but an underestimation of $28 \%$ for the upper column. The use of an adjustment factor to offset the overestimation for the lower column will magnify the underestimation for the upper column, and thus make the design over-conservative. 


\section{Acknowledgment}

The findings in this paper were presented by the first author in the School of Civil and Environmental Engineering at Cornell University, Ithaca, New York, on 24 October 2000. The authors would like to thank Ronald Ziemian for making the seminar possible.

\section{Appendix I. References}

Aristizabal-Ochoa, J. D. (1997) "Story stability of braced, partially braced and unbraced frames: Classical approach.” J. Struct. Engrg., 123 (6), 799-807.

AISI (1996). Specification for the Design of Cold-Formed Steel Structural Members, American Iron and Steel Institute, Washington.

ASCE (1997). Effective Length and Notional Load Approaches for Assessing Frame Stability: Implications for American Steel Design, American Society of Civil Engineers, New York.

Attard, M. M. (1992) “Flexural-torsional buckling of mono-symmetric columns." $J$. Construct. Steel Res., 23 (2), 117-126.

Baldassino, N., and Hancock, G. J. (1999) “Distortional buckling of cold-formed steel storage rack sections including perforations.” Proc., Light-Weight Steel and Aluminium Structures, Helsinki, 21-23 June 1999, P. Makelainen and P. Hassinen, eds., Elsevier Science, Amsterdam, 131-138.

Baldassino, N., Bernuzzi, C., and Zandonini, R. (2000) "Experimental analysis on key components of steel storage pallet racking systems.” Proc., Structural Failure and Plasticity, Melbourne, X. L. Zhao and R. H. Grzebieta, eds., Pergamon, Amsterdam, 859864.

Bridge, R. Q., and Fraser, D. J. (1987) "Improved G-factor method for evaluating effective lengths of columns.” J. Struct. Engrg., 113 (6), 1341-1356. 
Chajes, A., and Winter, G. (1965) “Torsional-flexural buckling of thin-walled members.” J. Struct. Div., ASCE, 91 (4), 103-124.

Chan, S. L., and Zhou, Z. H. (1994) "Pointwise equilibrium polynomial element for nonlinear analysis of frames.” J. Struct. Eng., 120 (6), 1703-1717.

Cheong-Siat-Moy, F. (1986) “K-factor paradox.” J. Struct. Eng., 112 (8), 1647-1760.

Cheong-Siat-Moy, F. (1995) “Misconceptions regarding the K-factor.” Proc., Structural Stability and Design, Sydney, 30 October - 1 November 1995, S. Kitipornchai, G. J. Hancock and M. A. Bradford, eds., A. A. Balkema, Rotterdam, 243-248.

Cheong-Siat-Moy, F. (1999) “Improved K-factor formula.” J. Struct. Engrg., 125 (2), 169174.

Conci, A. (1992) "Large displacement analysis of thin-walled beams with generic open section.” Int. J. Numer. Meth. Engrg., 33 (12), 2109-2127.

Conci, A., and Gattass, M. (1990) "Natural approach for geometric nonlinear analysis of thinwalled frames.” Int. J. Numer. Meth. Engrg., 30 (2), 207-231.

Davies, J. M. (1992) “Down-aisle stability of rack structures,” Proc., $11^{\text {th }}$ Int. Specialty Conf. Cold-Formed Steel Structures, St. Louis, Missouri, 20-21 October, 417-435.

Duan, L., and Chen, W. F. (1988) "Effective length factors for columns in braced frames.” J. Struct. Engrg., 114 (10), 2357-2370.

Duan, L., and Chen, W. F. (1989) "Effective length factors for columns in unbraced frames." J. Struct. Engrg., 115 (1), 149-165.

Dunai, L., Hegedus, T., Kaltenbach, L., and Adany, S. (1997) "Experimental and numerical studies on the stability of racking frames.” Stability and Ductility of Steel Structures, T. Usami, ed., Japanese Society of Steel Construction, Tokyo, Japan, 647-652.

Essa, H. (1997) "Stability of columns in unbraced frames.” J. Struct. Engrg., 123 (7), 952957. 
FEM (1998). Recommendations for the Design of Static Steel Pallet Racking and Shelving, FEM 10.2.02, Federation Europeene de La Manutention, Birmingham, UK.

Godley, M. H. R., Beale, R. G., and Feng, X. (2000) “Analysis and design of down-aisle pallet rack structures.” Comp. Struct., 77 (4), 391-401.

Hancock, G. J. (1985) “Distortional buckling of steel storage rack columns.” J. Struct. Eng., 111 (12), 2770-2783.

Hancock, G. J., Murray, T. M., and Ellifritt, D. S. (2001). Cold-formed steel structures to the AISI Specification, Marcel Dekker, New York.

Hellesland, J., and Bjorhovde, R. (1996) “Improved frame stability analysis with effective lengths.” J. Struct. Engrg., 122 (11), 1275-1283.

Hsiao, K. M., and Lin, W. Y. (2001) "Co-rotational formulation for geometric nonlinear analysis of doubly symmetric thin-walled beams.” Comp. Meth. Appl. Mech. Engrg., 190 (45), 6023-6052.

Hsiao, K. M., and Lin, W. Y. (2000) “A Co-rotational formulation for thin-walled beams with mono-symmetric open sections.” Comp. Meth. Appl. Mech. Engrg., 190 (8-10), 11631185.

Kishi, N., Chen, W. F., and Goto, Y. (1997) "Effective length factor of columns in semirigid and unbraced frames.” J. Struct. Engrg., 123 (3), 313-320.

Jennings, A. (1968) “Frame analysis including change in geometry.” J. Struct. Div., ASCE, 94 (ST3), 627-644.

Lewis, G. M. (1991) “Stability of rack structures.” Thin-Walled Struc., 12 (2), 163-174.

Li, T. Q., Choo, B. S., and Nethercot, D. A. (1995) "Connection element method for the analysis of semi-rigid frames.” J. Construct. Steel Res., 32 (2), 143-171.

Meek, J. L., and Tan, H. S. (1984) “Geometrically non-linear analysis of space frames by an incremental iterative technique.” Comp. Meth. Appl. Mech. Engrg., 47 (3), 261-282. 
Olsson, A. M. J., Sandberg, G. E., and Austrell, P. E. (1999) “Load-carrying capacity of damaged steel columns with channel sections.” J. Struct. Eng., 125 (3), 338-343.

Pekoz, T. (1979) “Design of cold-formed storage racks.” Proc., Int. Conf. Thin-Walled Structures: Recent Technology Advance and Trends in Design, Research and Construction, Glasgow, Scotland, 145-159.

RMI (1997). Specification for Design, Testing and Utilisation of Industrial Steel Storage Racks, Rack Manufacturers Institute, Charlotte, North Carolina.

Roos, O., and Hancock, G. J. (1986) "Flexural-torsional buckling of storage rack columns.” Proc., $8^{\text {th }}$ Int. Specialty Conf. Cold-Formed Steel Structures, 11-12 Nov 1986, St. Louis, Missouri, University of Missouri-Rolla.

SA (1993a). Steel Storage Racking, AS 4084-1993, Standards Australia, Homebush, New South Wales.

SA (1993b). Steel Storage Racking - Commentary, Supplement to AS 4084-1993, Standards Australia, Homebush, New South Wales.

SA (1998). Steel Structures, AS 4100-1998, Standards Australia, Homebush, New South Wales.

SA/SNZ (1996). Cold-Formed Steel Structures, AS/NZS 4600:1996, Standards Australia/Standards New Zealand.

SAA (1981). SAA Steel Structures Code, AS 1250-1981, Standards Association of Australia.

Smith, B. S., and Cruvellier, M. (1991) “General planar model for analysing high-rise structures.” J. Struct. Eng., 117 (11), 3228-3238.

Teh, L. H. (1998) “Towards 3D plastic-zone advanced analysis of steel frames,” PhD thesis, Department of Civil Engineering, University of Sydney, Australia.

Teh, L. H. (2001) “Cubic beam elements in practical analysis and design of steel frames.” Engrg. Struct., 23 (6), 631-642. 
Teh, L. H., and Clarke, M. J. (1997) “New definition of conservative internal moments in space frames.” J. Engrg. Mech., 123 (2), 97-106.

Teh, L. H., and Clarke, M. J. (1998) “Co-rotational and Lagrangian formulations of elastic three-dimensional beam finite elements.” J. Construct. Steel Res., 48 (2-3), 123-144.

Teh, L. H., and Clarke, M. J. (1999) "Symmetry of tangent stiffness matrices of 3D elastic frame.” J. Engrg. Mech., 125 (2), 248-251.

Tide, R. H. R., and Calabrese, F. A. (1998) “Investigation of collapsed rack storage systems.” Thin-walled Structures, N. E. Shanmugam et al., eds., Elsevier, Oxford, 493-500.

Timoshenko, S. P., and Gere, J. M. (1961). Theory of Elastic Stability, $2^{\text {nd }}$ ed., McGraw-Hill, New York.

Trahair, N. S. (1993). Flexural-Torsional Buckling of Structures, E\&FN Spon, London.

White, D. W., and Hajjar, J. F. (1997) “Buckling models and stability design of steel frames: a unified approach.” J. Construct. Steel Res., 42 (3), 171-207. 
Table 1 Beam levels and backtie elevations

\begin{tabular}{|c|c|c|}
\hline & Beam level (mm) & Backtie elevation (mm) \\
\hline $\mathbf{1}$ & 1125 & 2750 \\
\hline $\mathbf{2}$ & 2550 & 4175 \\
\hline $\mathbf{3}$ & 3975 & 6350 \\
\hline $\mathbf{4}$ & 6150 & 8550 \\
\hline $\mathbf{5}$ & 8350 & 10750 \\
\hline $\mathbf{6}$ & 10500 & 13000 \\
\hline $\mathbf{7}$ & 12700 & 15100 \\
\hline $\mathbf{8}$ & 14850 & 17500 \\
\hline $\mathbf{9}$ & 17100 & 19500 \\
\hline $\mathbf{1 0}$ & 19250 & 21800 \\
\hline $\mathbf{1 1}$ & 21475 & 24400 \\
\hline $\mathbf{1 2}$ & 24200 & 26650 \\
\hline $\mathbf{1 3}$ & 27000 & \\
\hline
\end{tabular}


Table 2 Pallet beam section properties (rectangular hollow sections)

\begin{tabular}{|c|c|c|c|c|c|}
\hline Storey & Level & $\boldsymbol{A}\left(\mathbf{m m}^{\mathbf{2}}\right)$ & $\left.\boldsymbol{I}_{\boldsymbol{z}} \mathbf{( m m}^{\mathbf{4}}\right)$ & $\left.\boldsymbol{I}_{\boldsymbol{y}} \mathbf{( m m}^{\mathbf{4}}\right)$ & $\boldsymbol{J} \mathbf{( m m}^{\mathbf{4}} \mathbf{)}$ \\
\hline $\mathbf{2 - 3}$ & $1-2$ & 550 & 900,000 & 235,000 & 500 \\
\hline $\mathbf{4 - 1 1}$ & $3-10$ & 650 & $1,500,000$ & 280,000 & 550 \\
\hline $\mathbf{1 2 - 1 3}$ & $11-12$ & 700 & $2,100,000$ & 320,000 & 600 \\
\hline Top & $(13)$ & 500 & 600,000 & 200,000 & 400 \\
\hline
\end{tabular}


Table 3 Column and cross-aisle brace section properties (mono-symmetric channels)

\begin{tabular}{|l|c|c|c|c|c|c|}
\hline & $\left.\boldsymbol{A} \mathbf{( m m}^{\mathbf{2}}\right)$ & $\left.\boldsymbol{I}_{\boldsymbol{Z}} \mathbf{( m m}^{\mathbf{4}}\right)$ & $\left.\boldsymbol{I}_{\boldsymbol{y}} \mathbf{( m m}^{\mathbf{4}}\right)$ & $\left.\boldsymbol{J} \mathbf{( m m}^{\mathbf{4}}\right)$ & $\left.\boldsymbol{C}_{w} \mathbf{( m m}^{\mathbf{6}}\right)$ & $\boldsymbol{z}_{s} \mathbf{( \mathbf { m m } )}$ \\
\hline $\begin{array}{l}\text { Lower column } \\
\text { (up to Storey 5) }\end{array}$ & 800 & $1,300,000$ & 700,000 & 1,500 & $2.5 \times 10^{9}$ & 85.0 \\
\hline $\begin{array}{l}\text { Upper column } \\
\text { (from Storey 6) }\end{array}$ & 600 & $1,000,000$ & 500,000 & 700 & $2.0 \times 10^{9}$ & 90.0 \\
\hline $\begin{array}{l}\text { Cross-aisle } \\
\text { brace }\end{array}$ & 130 & N/A & 10,000 & 100 & N/A & 20.0 \\
\hline
\end{tabular}


Table 4 Down-aisle brace, horizontal brace and backtie section properties

\begin{tabular}{|l|c|c|c|c|c|}
\hline & Section shape & $\boldsymbol{A}\left(\mathbf{m m}^{\mathbf{2}}\right)$ & $\boldsymbol{I}_{\boldsymbol{z}}\left(\mathbf{m m}^{\mathbf{4}}\right)$ & $\boldsymbol{I}_{\boldsymbol{y}}\left(\mathbf{m m}^{\mathbf{4}}\right)$ & $\boldsymbol{J} \mathbf{( \mathbf { m m } ^ { \mathbf { 4 } } )}$ \\
\hline Down-aisle brace & Flat strip & 600 & N/A & N/A & N/A \\
\hline Horizontal brace & Equal angle & 568 & N/A & N/A & N/A \\
\hline Backtie in spine tower & SHS & 841 & 716,000 & 716,000 & $1,115,000$ \\
\hline Rack spacer & SHS & 541 & 195,000 & 195,000 & 321,000 \\
\hline
\end{tabular}

*SHS = square hollow section 
Table 5 Linear buckling analysis results of 3D models

\begin{tabular}{|l|c|c|c|c|c|}
\hline & \multicolumn{3}{|c|}{ Feature in computer model } & \multirow{2}{*}{$\begin{array}{c}\text { Buckling } \\
\text { shape }\end{array}$} & $\begin{array}{c}\text { Load } \\
\text { factor }\end{array}$ \\
\cline { 2 - 4 } & $\begin{array}{c}\text { Wagner } \\
\text { effect }\end{array}$ & $\begin{array}{c}\text { Warping } \\
\text { torsion }\end{array}$ & $\begin{array}{c}\text { Shear-centre } \\
\text { eccentricity }\end{array}$ & \\
\hline Model 1 & $\mathrm{N}$ & $\mathrm{N}$ & $\mathrm{N}$ & Fig. 8 & 2.14 \\
\hline Model 2 & $\mathrm{Y}$ & $\mathrm{N}$ & $\mathrm{N}$ & Fig. 9 & 0.45 \\
\hline Model 3 & $\mathrm{Y}$ & $\mathrm{Y}$ & $\mathrm{N}$ & Fig. 10 & 2.95 \\
\hline Model 4 & $\mathrm{Y}$ & $\mathrm{Y}$ & $\mathrm{Y}$ & Fig. 11 & 2.48 \\
\hline
\end{tabular}


Table 6 Percent difference in elastic buckling stresses between 2D procedures and $3 \mathrm{D}$ rational frame buckling analysis

\begin{tabular}{|l|c|c|}
\hline & Lower column & Upper column \\
\hline 2D rational buckling analysis & +11 & -28 \\
\hline $\boldsymbol{G}_{\mathrm{A}}, \boldsymbol{G}_{\mathrm{B}}$; braced frame & +70 & -12 \\
\hline $\boldsymbol{G}_{\mathrm{A}}, \boldsymbol{G}_{\mathrm{B}} ;$ unbraced frame & -64 & -71 \\
\hline $\boldsymbol{K}_{\mathbf{z}}=\mathbf{1 . 0}$ & +41 & -21 \\
\hline $\boldsymbol{K}_{\mathbf{z}}=\mathbf{1 . 7}$ & -46 & -59 \\
\hline
\end{tabular}




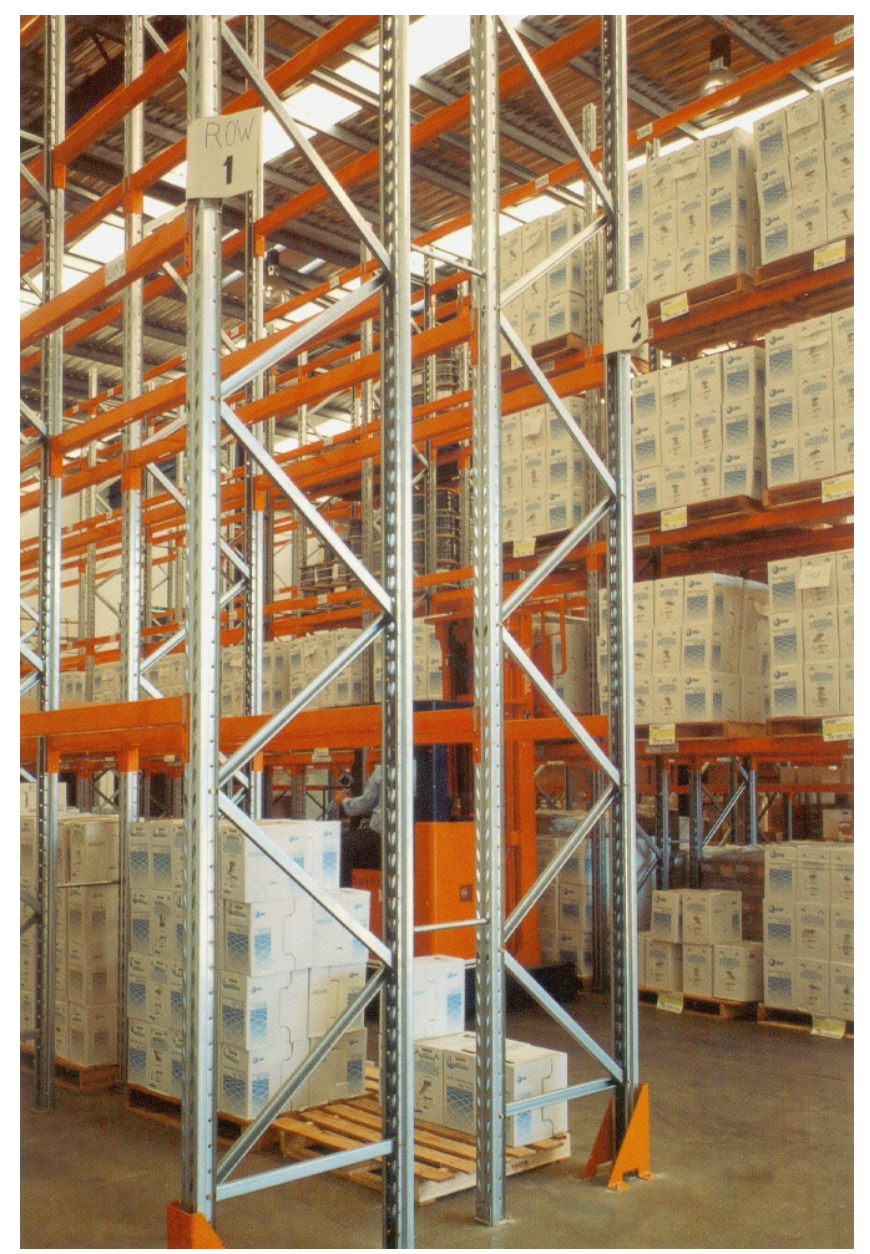

Fig. 1 Adjustable pallet rack frames in service 


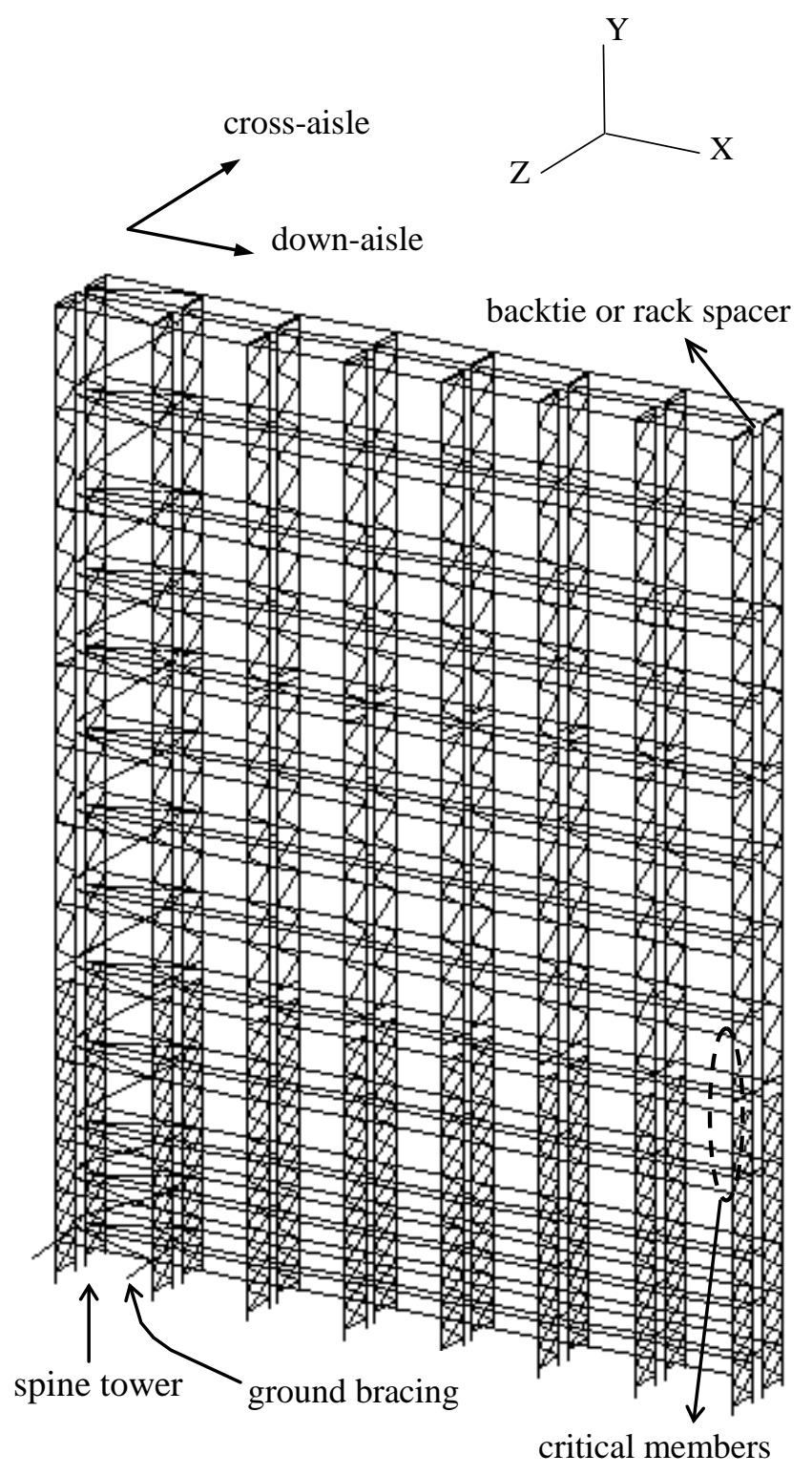

Fig. 2 Double-sided frame model 


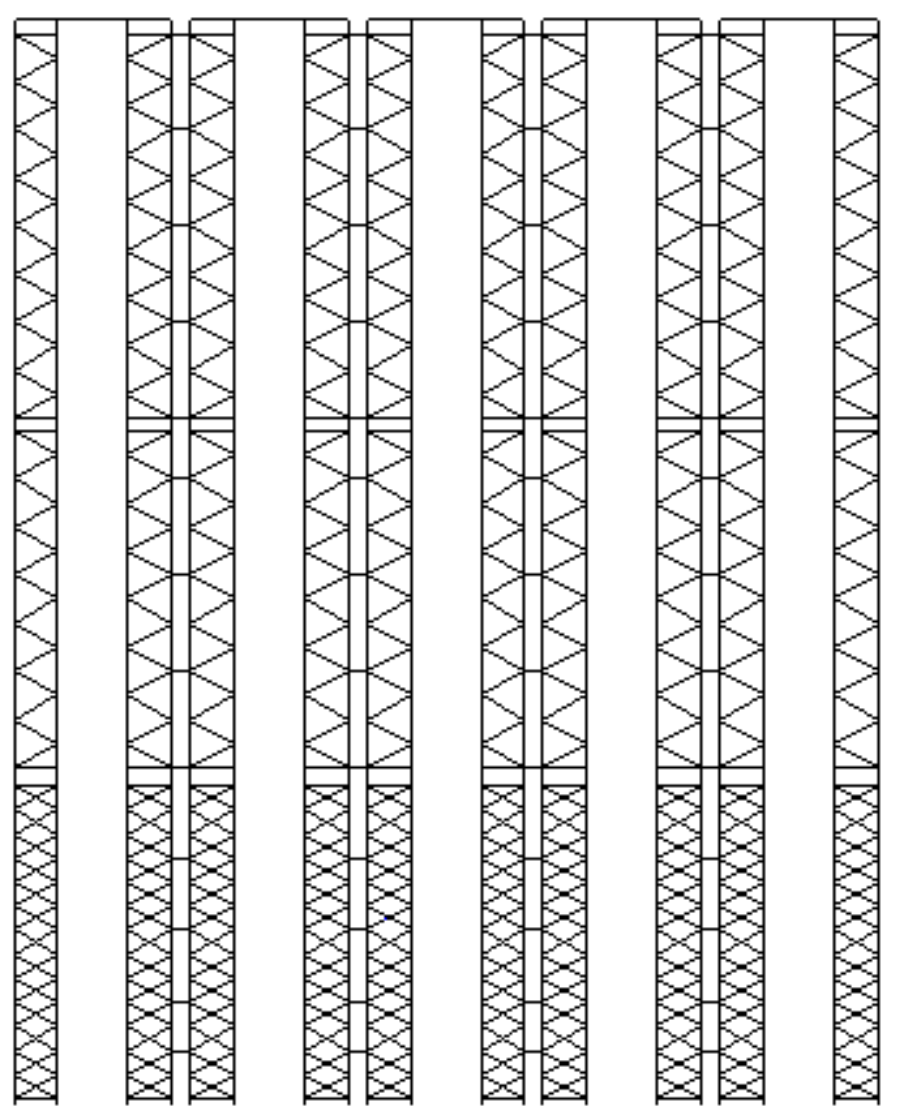

Fig. 3 Cross-aisle view of a group of four double-sided frames and two single-sided frames 

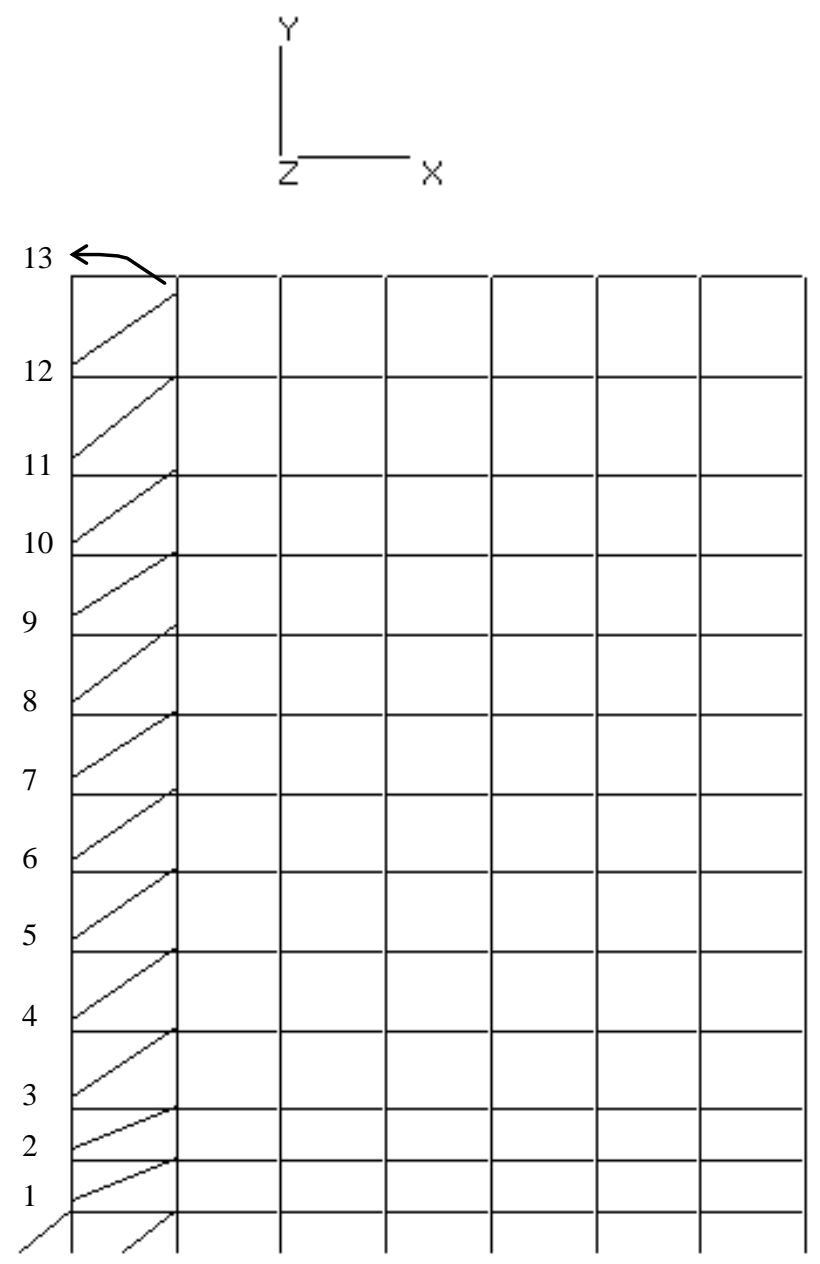

Fig. 4 Level numbers in Table 1 


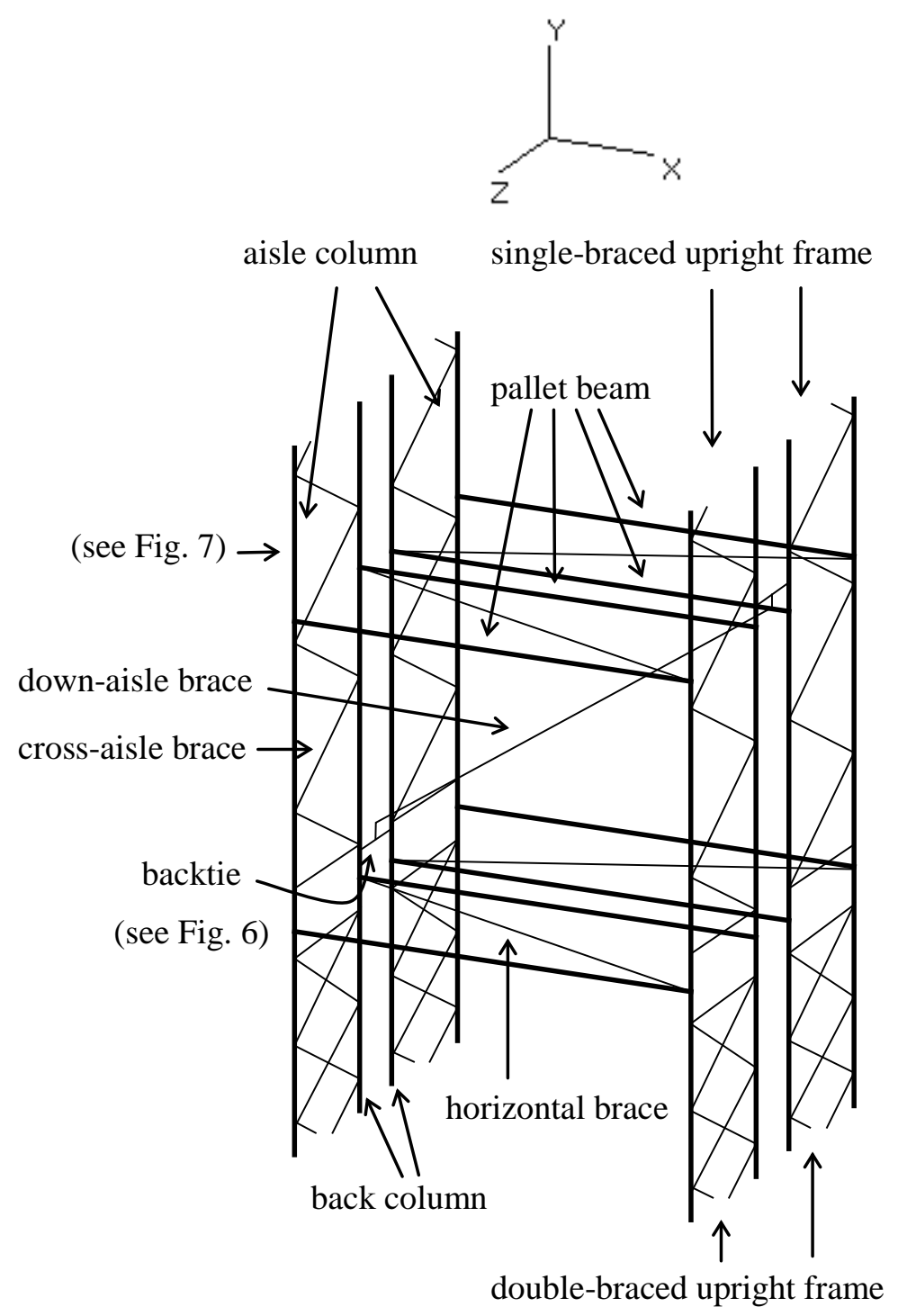

Fig. 5 Components of a spine tower in a double-sided frame 

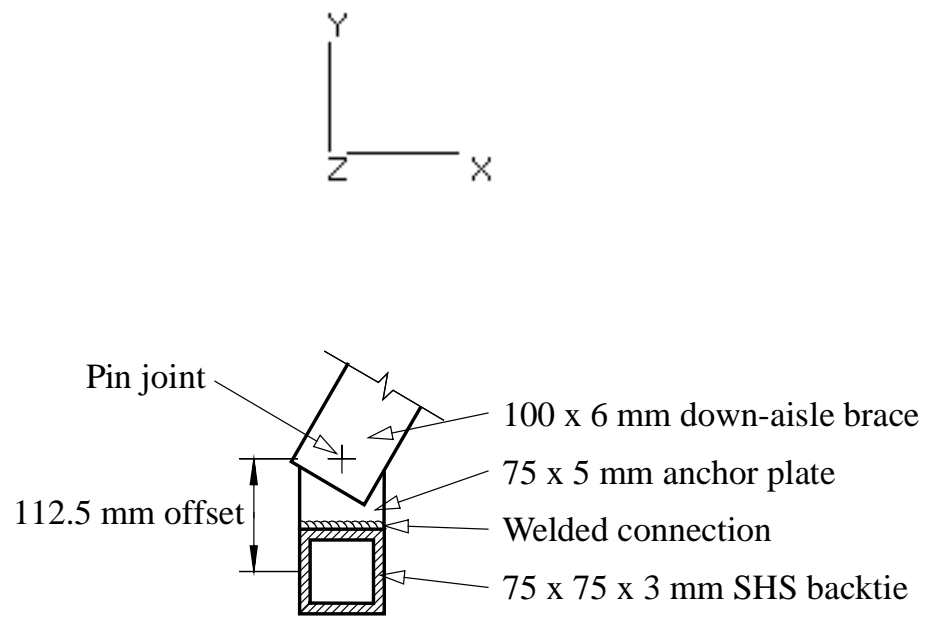

Fig. 6 Backtie details, elevation (see Fig. 5 for location in the frame) 


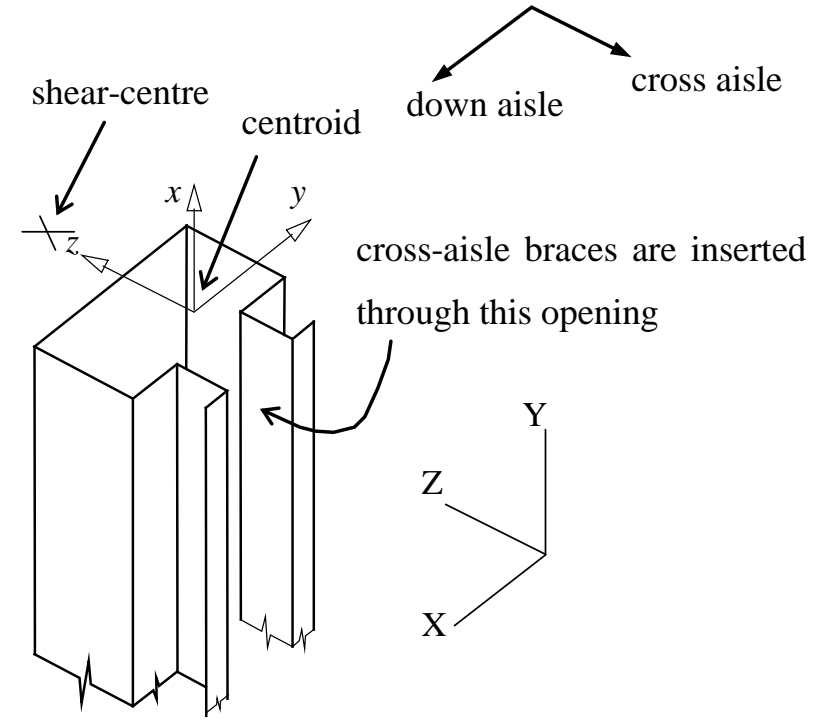

Fig. 7 Mono-symmetric column section (see Fig. 5 for location in the frame) 

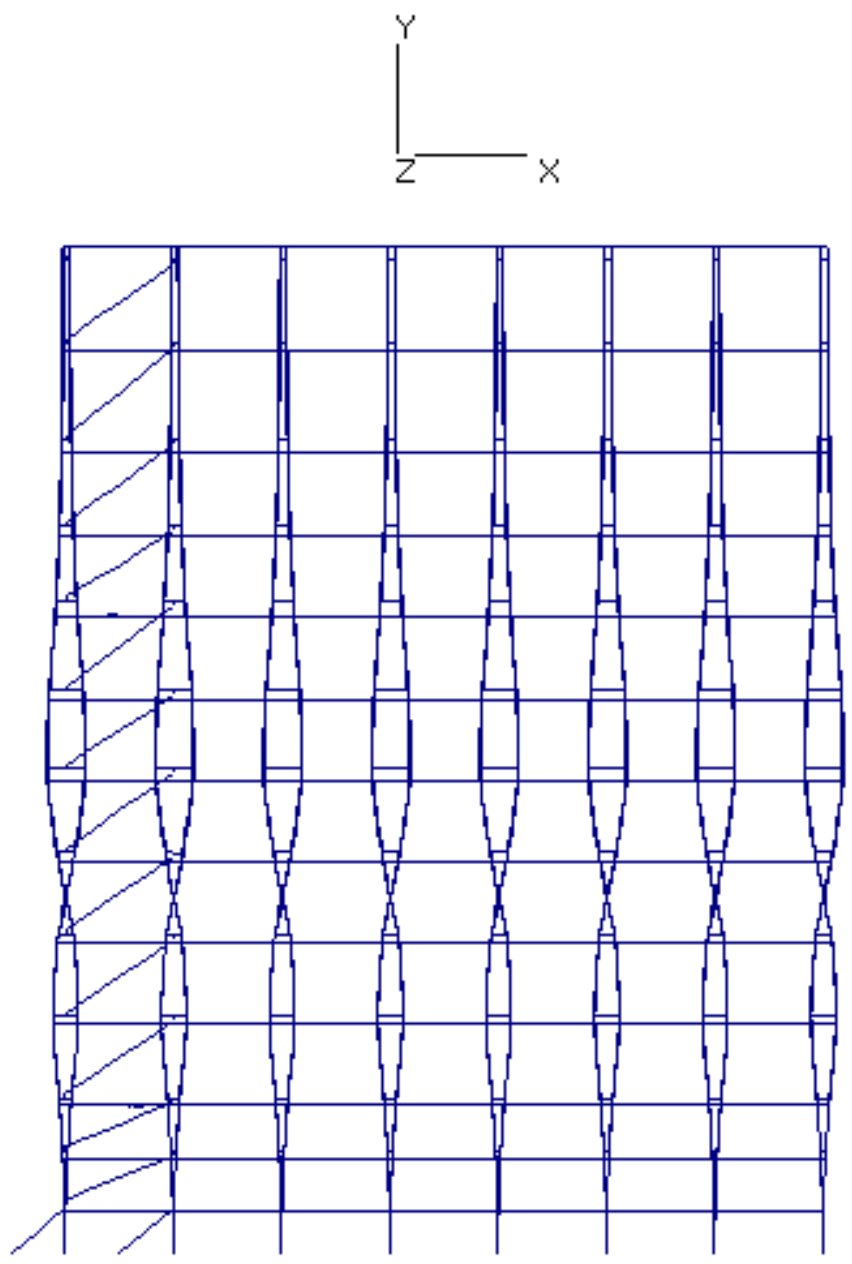

Fig. 8 Buckling of double-sided frame with simple elements (Model 1) 

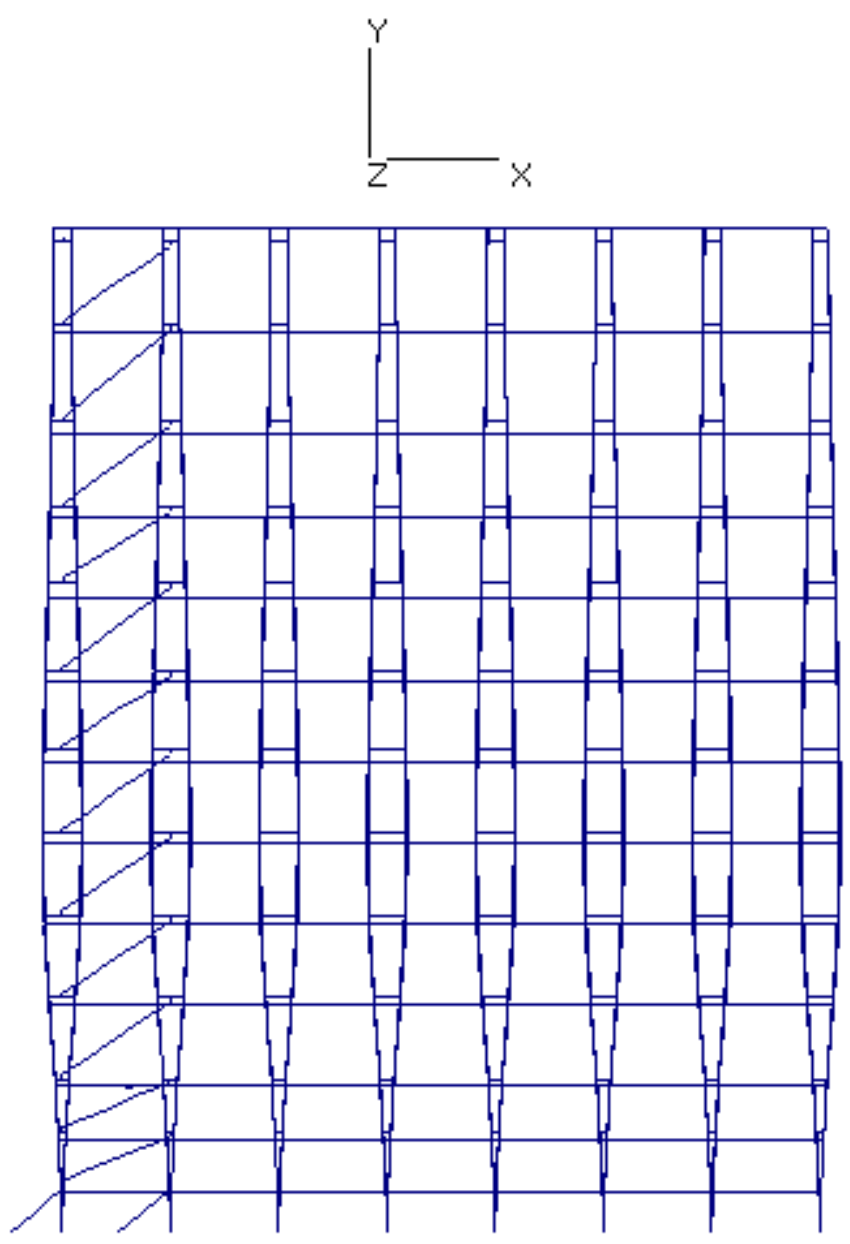

Fig. 9 Buckling of double-sided frame due to Wagner effect (Model 2) 


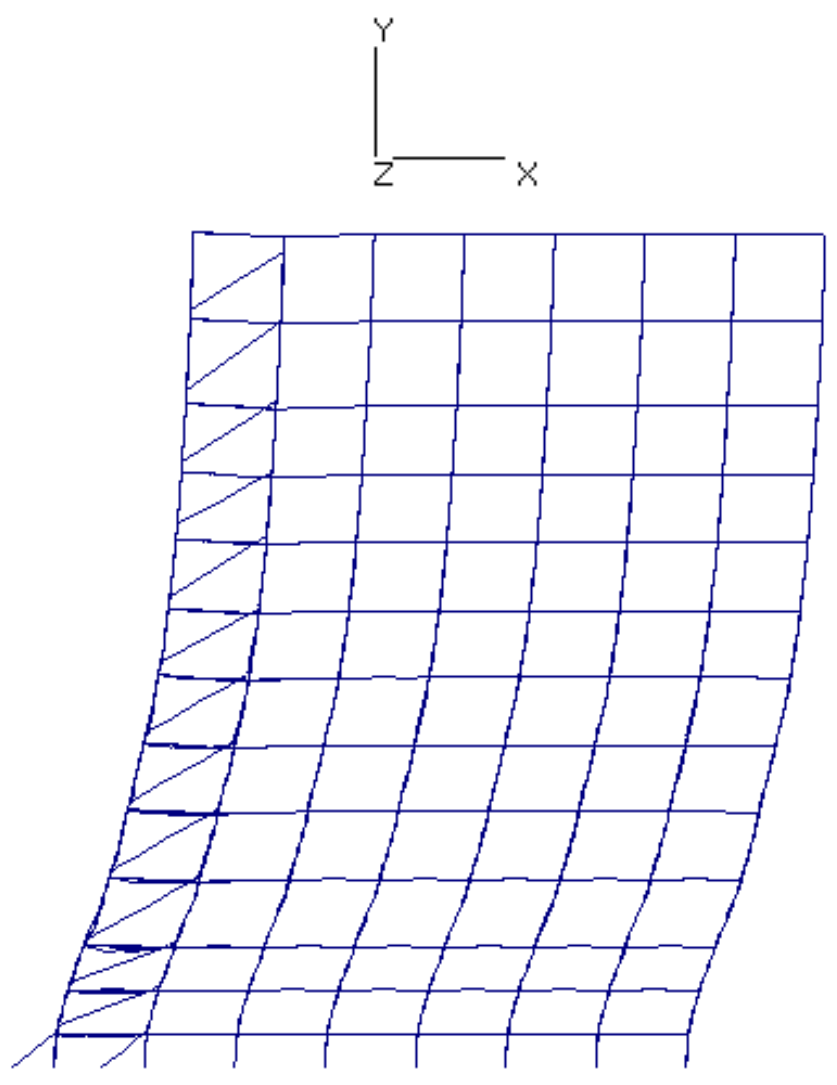

Fig. 10 Buckling of double-sided frame with Wagner effect and warping torsion rigidity included (Model 3) 


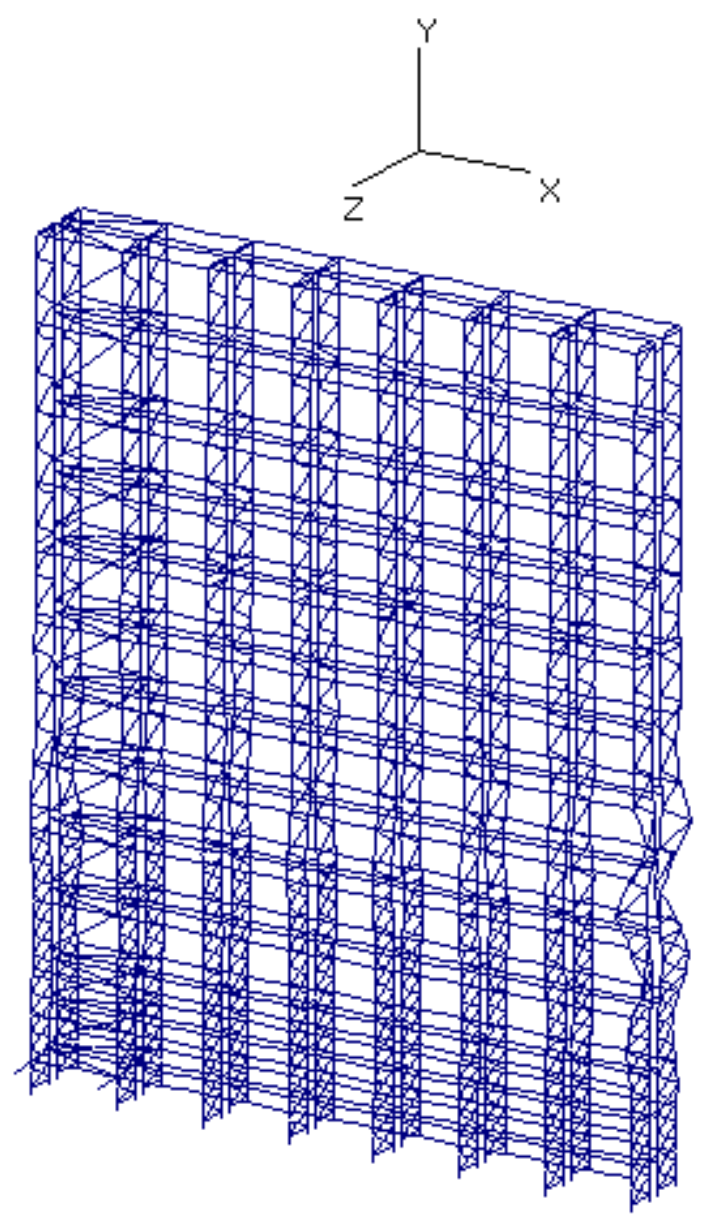

Fig. 11 Buckling of double-sided frame with Wagner effect, warping torsion and shear-centre eccentricity included (Model 4) 


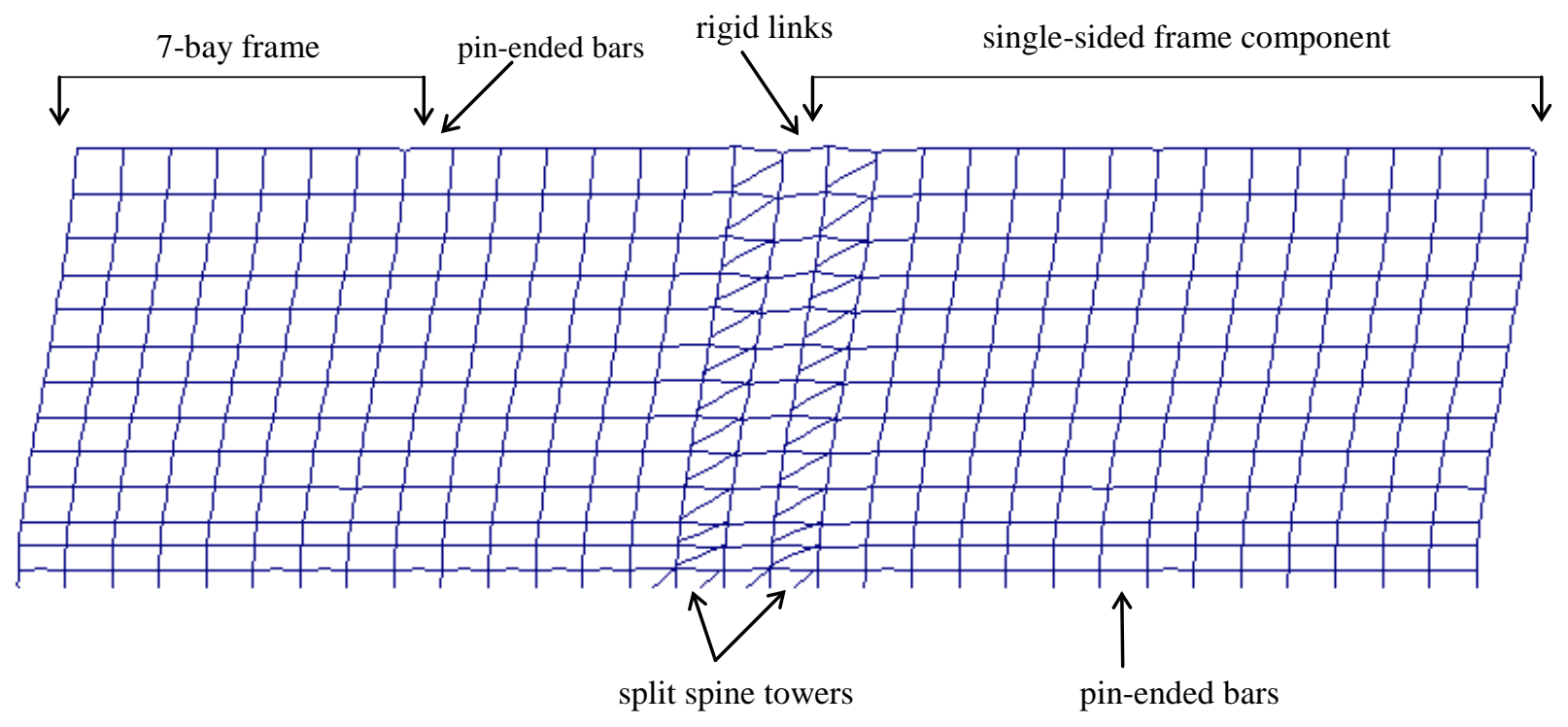

Fig. 12 Buckling of planar model for double-sided frame 